\title{
Precision Medicine in Pediatric Cancer: Current Applications and Future Prospects
}

\author{
Atif A. Ahmed ${ }^{1,2, *(\mathbb{C}}$, Divya S. Vundamati ${ }^{1}$, Midhat S. Farooqi ${ }^{1,2} \mathbb{D}$ and Erin Guest ${ }^{1,2} \mathbb{C}$ \\ 1 Departments of Pathology and Pediatric Hematology-Oncology, University of Missouri School of Medicine, \\ Kansas City, MO 64108, USA; dsvr5b@mail.umkc.edu (D.S.V.); msfarooqi@cmh.edu (M.S.F.); \\ eguest@cmh.edu (E.G.) \\ 2 Children's Mercy Hospital, Kansas City, MO 64108, USA \\ * Correspondence: aahmed@cmh.edu; Tel.: +1-8162343234; Fax: +1-8168021492
}

Received: 14 November 2018; Accepted: 7 December 2018; Published: 13 December 2018

\begin{abstract}
Precision oncologic medicine is an emerging approach for cancer treatment that has recently taken giant steps in solid clinical practice. Recent advances in molecular diagnostics that can analyze the individual tumor's variability in genes have provided greater understanding and additional strategies to treat cancers. Although tumors can be tested by several molecular methods, the use of next-generation sequencing (NGS) has greatly facilitated our understanding of pediatric cancer and identified additional therapeutic opportunities. Pediatric tumors have a different genetic make-up, with a fewer number of actionable targets than adult tumors. Nevertheless, precision oncology in the pediatric population has greatly improved the survival of patients with leukemia and solid tumors. This review discusses the current status of pediatric precision oncology and the different clinical scenarios in which it can be effectively applied.
\end{abstract}

Keywords: actionable mutations; next generation sequencing; pediatric cancer; precision medicine

\section{Introduction}

The management of patients with cancer can sometimes be challenging. These challenges are frequently attributed to tumor recurrence/metastasis during or following treatment or initial therapy resistance. In such situations, the use of novel targeted therapy has greatly revolutionized cancer treatment and is largely based on blocking actionable gene mutations or over-expressed signaling transduction pathways. Recent advances in molecular diagnostics have fueled the personalized approach to such cancer treatment. The fact that cancer is a genomic disease is the basis or foundation of precision oncology and targeted therapy [1,2]. Although early experiments on precision treatment started more than a century ago, only in the last decade has this term gained practical momentum in cancer treatment [3]. Precision medicine and its applications have started to fulfill their promise and their use have become more common in the last five years and in more than one cancer type [4].

Precision cancer treatment is largely based on matching the patient's tumor mutations with the appropriate targeted therapy. A variety of genetic or molecular assays are currently available for testing on tumors including cytogenetic fluorescent in situ hybridization (FISH) tests, polymerase chain reaction (PCR) single gene testing, and single nucleotide polymorphism (SNP)-based microarrays [5]. In recent years, the practical use of such molecular tests in the diagnosis, risk assessment, response measurement and treatment of cancer patients has greatly expanded. However, the greatest benefit has come from next-generation sequencing (NGS) methods which include whole-genome sequencing (WGS), whole-exome sequencing (WES) and RNA sequencing (RNAseq), that offer many advantages over the single-drug, single-genetic test models [6]. NGS is a fast technology that allows for massively parallel sequencing of genomic fragments generating thousands to millions of short "reads" in a 
single run. It can detect point mutations including single nucleotide polymorphisms as well as small (generally, less than 20-30 base pairs) insertions/deletions (indels) in large numbers of genes at once. Coupled with powerful computational resources and tools to store, process and analyze the data, NGS can also identify unanticipated targetable mutations, copy number alterations, differentially expressed genes, and gene fusions [7]. The progressive decrease in the cost of sequencing (from more than $\$ 300,000$ for an entire genome in 2008 to currently $<\$ 1000$ ) and the increase in the number of genes tested in a typical sequencing panel (from 50 to over 400 genes) has allowed for the high yield extraction of data and presented enormous opportunities to study rare and difficult to treat neoplasms [8]. Other advantages of NGS are that it can be performed from a low amount of input DNA, which is beneficial when small needle biopsies are obtained, and that it can be performed on DNA extracted from formalin-fixed, paraffin-embedded tissue.

\section{Pediatric Cancer Genome}

Most cancers harbor somatic gene mutations, variants, or fusions that can be detected by NGS in clinically approved platforms. In a recent genetic analysis of 439 adult patients with cancer, $90 \%$ had at least one actionable or targetable mutation in their tumor [9]. In the pediatric population, precision oncology is an area of highly active research, with efforts focused on developing targeted therapies for patients who are not cured with standard treatment. Currently, however, the applications of molecular-based therapeutics in children are rather limited compared to the field of precision oncology for adult-onset cancers. Many of the advances in pediatric precision oncology thus far have been in leukemia, as opposed to solid tumors [10]. Pediatric malignancies are much rarer and are more often induced by inherited or sporadic errors in development rather than by environmental exposure. Thus the genomic landscape of alterations in pediatric cancer shows significant differences from adult cancers in terms of mutation frequency and type of altered genes [11]. With few exceptions, pediatric cancers exhibit a lower mutational burden with far fewer single nucleotide variants (SNVs) and small indels. On the other hand, childhood malignancies have a relatively high prevalence of specific structural variations (e.g., gene fusions and chromosomal rearrangements) and exhibit high specificity of associations with histologic tumor subtypes (see Table 1) [12,13]. Most of the genetic alterations in pediatric leukemias and solid tumors involve well-known genes and oncogenic pathways such as receptor tyrosine kinases, phosphoinositide 3-kinase-AKT and related pathways, TP53, CDK12, NOTCH1, ARID1 and include amplification of other genes such as MYCN, MCL1, MDM2 and others [14,15].

Table 1. Genetic background of selected common pediatric tumors showing common structural rearrangements and recurrently mutated genes.

\begin{tabular}{ccc}
\hline Tumor & Structural Rearrangements & Significantly Mutated Genes \\
\hline Ewing's sarcoma & EWS-ETS & STAG2, CDKN2A, TP53 \\
\hline Ewing's-like round cell sarcoma & $\begin{array}{c}\text { CIC-FOX4; CIC-DUX4; BCOR-CCNB3; } \\
\text { EWS-POU5F1/PATZI }\end{array}$ \\
\hline Alveolar rhabdomyosarcoma & PAX3/PAX7-FOXO1; PAX3-NCOA1 & $\begin{array}{c}\text { BCOR, PIK3CA, GAB1, PTEN, ARID1A, ROBO1, AKAP9, } \\
\text { NEB, C15orf2, PTPRO, COL5A2, PXDNL, NLRC5, TTN }\end{array}$ \\
\hline $\begin{array}{c}\text { Fusion-negative } \\
\text { rhabdomyosarcoma }\end{array}$ & None & $\begin{array}{c}\text { FGFR4, RAS, AKT, PIK3CA, MYOD1, DICER1, CTNNB1, } \\
\text { FBXW7, BCOR, TP53 }\end{array}$ \\
\hline Osteosarcoma & None & TP53, MDM2, RB1, ATRX, DLG2, PTEN \\
\hline Neuroblastoma & None & ALK, MYCN amplification, ATRX, TERT, PTPN11, \\
ARID1A, ARID1B, NF1, RAS, BRAF, FGFR1
\end{tabular}

More complete information can be found in the Childhood Cancer Genomics PDQ [15]. 


\section{Precision Applications in Childhood Cancer}

Several methods can be adopted for molecular precision analysis. Whole-exome, whole-genome, and RNA sequencing can be performed separately or complemented with methylation and expression microarray analysis. DNA methylation-based molecular diagnostics are currently being incorporated in the classification of pediatric central nervous system tumors [16]. An increasing number of gene-based targeted sequencing panels also are commercially available and are frequently used in clinical practice. Targeted sequencing improves the ability to detect low level clonal variants within a tumor, compared to WGS or WES studies [17].

Although comprehensive molecular testing has been advocated for all pediatric tumors [18], it is also important to identify patient populations that may receive the maximal benefit from molecularly targeted therapy and accelerated development of novel drugs for early phase clinical trials. The most efficient clinical and practical use of tumor sequencing can be further highlighted in these specific scenarios (Figure 1):

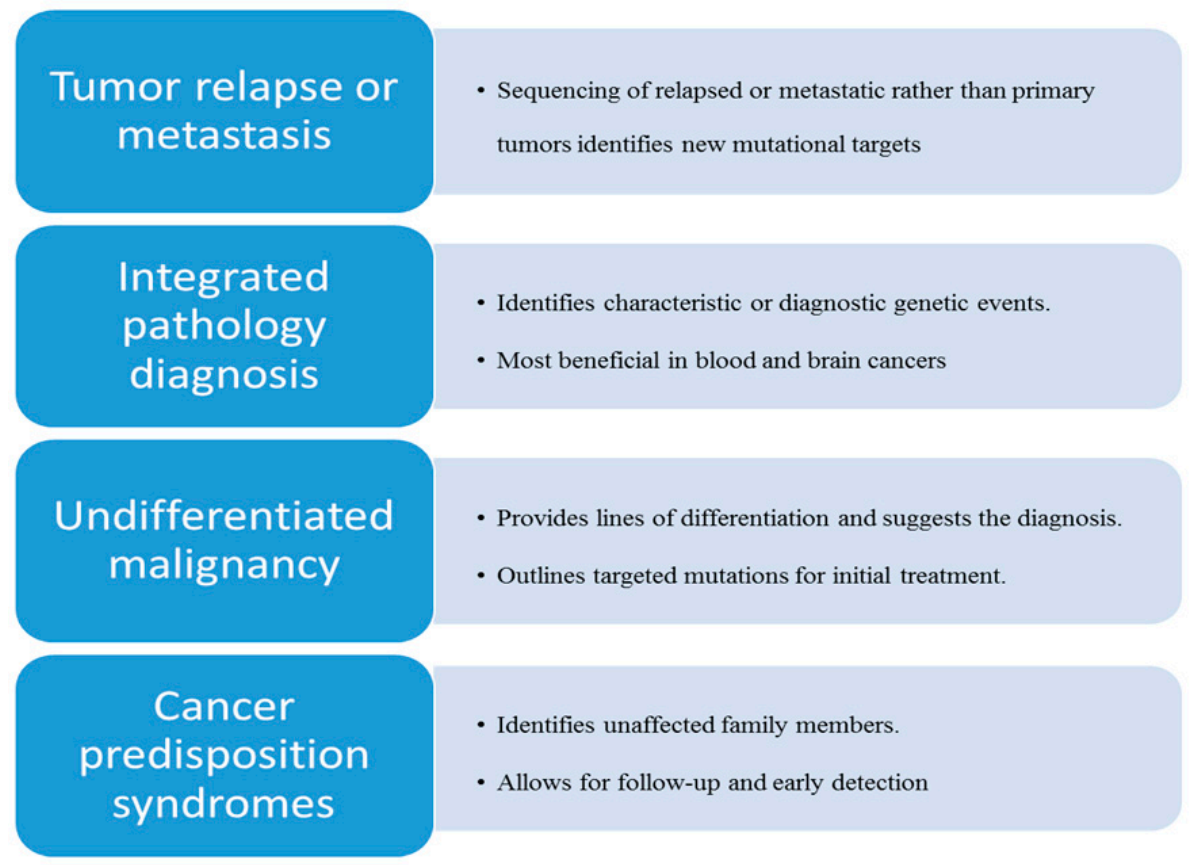

Figure 1. Most efficient use and benefits of next generation sequencing in pediatric cancer.

\subsection{Tumor Recurrence or Metastasis during Therapy}

Pediatric cancers may occasionally recur or metastasize during or after completion of standard therapy. Relapsed tumors harbor more genetic alterations than primary tumors [11]. Tumor recurrence and metastasis have a significant adverse effect on the prognosis. When clinicians have exhausted all available standard treatment options, molecular precision methods can provide additional strategies. In some series, WES has provided clinically informative results in the majority ( $>90 \%)$ of adult patients with metastatic cancer $[19,20]$. In pediatric cancer, the number of actionable mutations has been reported to be much lower than that in adults, reflecting the different nature of these tumors. In a cohort of 91 young patients with relapsed or refractory cancer, only 42 patients (46\%) had actionable findings that changed their cancer management [21]. Of 48 pediatric patients with recurrent or refractory cancer, clinically actionable findings were identified in $69 \%$ of patients, with the most efficient method being WES, followed by SNP array and RNAseq [22]. Despite the lower prevalence of actionable mutations, targeted therapy gives pediatric oncologists further hope in the treatment of refractory or relapsed pediatric cancers. In a case-controlled study of nine pediatric patients with refractory sarcoma, targeted therapy resulted in improvement of the overall survival to 8.83 months 
versus 4.93 months, and improvement of the progression-free survival to 6.17 months versus 1.6 months in the control group [23]. However, because of a possible increase in the number of mutations and changes in the mutational spectrum, the importance of testing relapsed or metastatic rather primary tumors cannot be over-emphasized [24].

Multidisciplinary management of cancers in an institutional molecular tumor board has led to better implementation or translation of NGS results into clinical actions for patients with refractory and poor prognosis cancers [25]. The major barriers to implementation of genomically guided therapy are the clinical status of the patient and access to off-label medications $[25,26]$. Reimbursement by third party payers either government-sponsored or from the private sector is also a major challenge to accessibility in many countries around the world [27].

\subsection{Integrated Morphologic Molecular Diagnosis}

The World Health Organization (WHO) diagnostic criteria for pediatric tumors, including most hematologic and brain tumors, are specified with integrated input from morphologic and molecular findings, reflecting the importance of molecular testing in clinical practice. Currently, many diagnostic genetic aberrations are tested by more routine molecular tests such as FISH and PCR. However, genomic sequencing is a sensitive technology for detecting diagnostic molecular aberrancies, can shed light on tumor heterogeneity and highlight differences (or similarities) between various pediatric and adult neoplasia. NGS can offer more accurate and comprehensive information on characteristic translocation partners, and identify targetable mutations that can lead to better treatments and cures. It has the potential to change or refine the morphologic diagnosis, offer prognostic information and direct care towards novel therapeutic agents [28]. After genomic profiling of 31 pediatric patients with brain tumors, the pathologic diagnosis was amended for 6 patients $(19 \%)$, pathogenic germline mutations were detected, and potentially targetable alterations were identified in 19 patients (61\%) [29]. A similar positive impact has been noted in pediatric hematologic malignancies. In 101 pediatric patients with high risk blood disorders tested with WES or RNAseq, clinically impactful findings were identified in $66 \%$ and potentially actionable mutations were present in $38 \%$ of cases [30]. In another cohort of 56 patients with high-risk hematologic malignancies and blood disorders, NGS findings contributed to the refinement of diagnosis and prognosis for 34\% of patients [31]. Thus, routine testing of primary tumors by NGS is highly recommended for pediatric hematologic disorders and brain tumors and may be offered to other tumors as well.

\subsection{Targeted Therapy of Undifferentiated Malignancies}

In a rising number of cases, the treatment challenge stems from difficulties in classifying certain cancers that manifest with unusual or rare, non-characteristic morphology. Most often such cancers are labeled as undifferentiated malignancy or undifferentiated sarcoma after extensive histopathologic and immunophenotypic analysis. Undifferentiated sarcoma is commonly diagnosed when a soft-tissue tumor has no identifiable line of differentiation. These tumors represent a heterogeneous group of mesenchymal tumors with variable morphology that include spindle cell, pleomorphic, round cell, and epithelioid tumor variants. Undifferentiated sarcomas in children have variable outcomes and it is not possible to tailor the treatment to a specific disease type. In such patients, the routine use of NGS could increase diagnostic accuracy by determining the cell type of origin, identify molecularly-targeted therapies to try, and provide support for the use of other interventions, such as surgical resection and/or radiation therapy. Furthermore, it may help to better understand the patient's prognosis for cure [32]. In the case of undifferentiated malignancies, early use of NGS can replace or decrease the number of other ancillary tests that are often requested during the processing of these tumors.

\subsection{Cancer Predisposition Syndromes (CPS)}

Recent studies indicate that a considerable percentage of childhood cancers are associated with CPS, some of which are inherited. The incidence of childhood cancers with genetic predisposition is 
estimated to be at least $10 \%$, and the number of newly identified CPS has been steadily growing due to increased awareness and more practical use of NGS-based methods in the classification of pediatric cancer [33]. WES of parent-child trios has become an increasingly popular method to identify causative genetic variants in the germline of families with clustering of malignancies and metachronous tumors, and is a very powerful tool for providing unique insights into inheritance patterns. Trio testing can identify inherited versus de novo mutations, parental mosaicism, type of aberration (e.g., SNV, $\mathrm{CNV}$, indels), and the dysregulation of cancer pathways (e.g., TP53, FA/BRCA) [34,35]. Tumors that fall into the category of CPS are diverse and include hamartomatous lesions, benign tumors, sarcomas, leukemia-lymphoma, and brain tumors (see Table 2) [36,37]. Clinicians and oncologists need to identify symptoms and signs of CPS correctly and refer patients for testing. NGS can also identify germline mutations in pre-symptomatic family members and allow for early detection of cancer through appropriate screening.

Table 2. Mutated genes and dysregulated signaling pathways in selected common cancer predisposition syndromes (see reference [37]).

\begin{tabular}{|c|c|c|c|}
\hline Cancer Predisposition Syndrome & Common Tumors & Mutated Genes & $\begin{array}{c}\text { Dysregulated Pathways } \\
\text { and Functions }\end{array}$ \\
\hline Li Fraumeni syndrome & $\begin{array}{l}\text { Leukemias, osteosarcoma, soft tissue } \\
\text { sarcoma, adrenocortical, brain tumors }\end{array}$ & TP53, CHEK2 & Cell cycle, apoptosis \\
\hline Familial adenomatous polyposis & $\begin{array}{c}\text { Colonic polyps, osteomas, desmoid, } \\
\text { thyroid and adrenal tumors }\end{array}$ & CTNNB1, MUTYH & $\mathrm{WNT} / \beta$-catenin \\
\hline Fanconi anemia & $\begin{array}{l}\text { Leukemias, hepatic tumors, upper } \\
\text { airways carcinomas }\end{array}$ & $\begin{array}{l}\text { FANC family of genes, } \\
\text { BRCA2 }\end{array}$ & DNA repair \\
\hline Nevoid basal cell carcinoma & Basal cell carcinomas, jaw cysts & $\mathrm{PTCH}$ & Sonic hedgehog $(\mathrm{SHH})$ \\
\hline Neurofibromatosis & $\begin{array}{l}\text { Peripheral nerve and nerve sheath } \\
\text { tumors, brain gliomas, GIST tumors }\end{array}$ & NF1 & $\begin{array}{l}\text { GTPase, RAS/MAPK } \\
\text { inactivation }\end{array}$ \\
\hline Von Hippel-Lindau & $\begin{array}{c}\text { Renal carcinoma, hemangioblastoma, } \\
\text { pheochromocytoma, pancreatic } \\
\text { tumors }\end{array}$ & $V H L$ & $\begin{array}{l}\text { HIF degradation, RNA } \\
\text { polymerase II regulation }\end{array}$ \\
\hline Dicer1 syndrome & Pleuropulmonary blastoma & Dicer1 & miRNA synthesis \\
\hline Xeroderma pigmentosum & Skin cancers & $X P$ family of genes & DNA repair \\
\hline $\begin{array}{l}\text { Hereditary } \\
\text { paraganglioma-pheochromocytoma }\end{array}$ & $\begin{array}{l}\text { Paraganglioma, pheochromocytoma, } \\
\text { renal cell carcinoma }\end{array}$ & $S D H$ & $\begin{array}{l}\text { Citric acid cycle, } \\
\text { oxidative } \\
\text { phosphorylation }\end{array}$ \\
\hline Ataxia telangiectasia & Leukemia, lymphoma & ATM & DNA repair \\
\hline Bloom syndrome & Leukemia, lymphoma & $B L M$ & DNA repair \\
\hline PTEN hamartoma & Breast, thyroid, GI polyps & PTEN & $\begin{array}{l}\text { Tyrosine kinase } \\
\text { de-phosphorylation }\end{array}$ \\
\hline $\begin{array}{l}\text { Hamartomatous polyposis } \\
\text { (Peutz-Jeghers/juvenile polyposis) }\end{array}$ & Gastrointestinal polyps & $\begin{array}{l}\text { LKB1/STK11; SMAD4; } \\
\quad \text { BMPR1A; ENG }\end{array}$ & DNA mismatch repair \\
\hline $\begin{array}{l}\text { Hereditary non-polyposis colorectal } \\
\text { cancer }\end{array}$ & $\begin{array}{l}\text { Colorectal cancer (very rare in } \\
\text { children) }\end{array}$ & $\begin{array}{c}\text { MLH1, MSH2, MSH6, or } \\
\text { PMS2 }\end{array}$ & DNA mismatch repair \\
\hline
\end{tabular}

\section{Future Prospects}

Early trials of precision oncology have improved our understanding of chemoresistance during the course of therapy, and have highlighted cancer heterogeneity and genomic complexity, including the role(s) of epigenetic modifiers in determining disease outcome. NGS has revealed many cancers carry mutations in genes encoding for transcriptional control. Epigenetic dysfunction and transcriptional dysregulation is frequent in many pediatric cancers, particularly leukemias [38,39]. Inhibition of transcriptional programs and epigenetic modification are potential areas of opportunity in precision medicine. Combination therapy with simultaneous disruption of two genes, termed synthetic lethality, is emerging as a new avenue of targeted precision. This is based on the hypothesis that poor prognosis cancers with loss-of-function mutations become "treatable" when two otherwise discrete and unrelated genes are targeted simultaneously. Epigenetic regulators and genes involved in DNA repair are particularly attractive targets for cancer therapy because of their altered gene expression patterns in 
cancer cells, compared with normal cells. Targeting of these regulatory genes can selectively kill cancer cells [40,41].

Another potential and novel area of precision medicine is the use of nanotechnology to overcome treatment resistance of cancer cells [42]. Delivery systems based on nanoparticles enhance antitumor drug uptake and selective intracellular accumulation in the cancer cell. Multifunctional nanoparticles can deliver drug combinations for synergistic therapy, and facilitate personalization of therapeutic regimens [43]. Superparamagnetic iron oxide nanoparticles (SPIONs) have magnetic properties, show excellent tumor-targeting efficiency, and are thus more effective in personalized cancer treatment [44]. Thus, the use of nanotechnology with combination therapy, whether traditional or targeted, is an ideal model for personalized medicine and may hopefully result in cancer cure and eradication [45].

The use of antibodies against tumor antigens and stimulation of the patient's own immune system to attack cancer cells are new forms of immunotherapy that have recently been used in patient treatments. A number of immunotherapy agents are in use or under investigation in pediatric cancer. Gemtuzumab ozogamicin has become part of the standard of care for pediatric patients with AML. Dinutuximab is an anti-GD2 antibody that is used in the treatment of neuroblastoma. Other immunotherapies under investigation include monoclonal antibodies (e.g., ganitumab), antibody-drug conjugates (e.g., brentuximab vedotin), bispecific T-cell engagers (e.g., blinatumomab), immune modulators (e.g., nivolumab, pembrolizumab, ipilimumab), and anti-cancer vaccines. Cellular therapies using modified T-cells have also been successfully employed. Based on their extraordinary ability to distinguish foreign peptides from self-antigens through their receptors, $\mathrm{T}$ cells are engineered with chimeric antigen receptors (CAR) designed for sustained proliferation and specific targeting of tumor cells. CAR-T cell therapy has been remarkably successful in treating patients with advanced refractory B cell malignancies through chimeric receptors targeting CD19 [46]. The success of CAR-T cell therapy in leukemia has been extrapolated to solid tumors where partial success has been demonstrated in sporadic case reports. A few clinical trials have reported using GD2-specific CAR-T cells for neuroblastoma and human epidermal growth factor receptor 2 (HER2) in medulloblastomas with non-dramatic results. A major challenge in CAR design is ensuring specificity for targeting tumor cells, while sparing healthy tissue and minimizing toxicity. Other major barriers need to be overcome for more successful CAR-T therapy. Reducing physical barriers in the extracellular matrix and eliminating the effect of an immunosuppressive microenvironment are some of the measures that ensure successful delivery of engineered T-cells to the tumor cells [47]. Although the outlook for CAR-T therapy promises superior benefits in the treatment of solid tumors, further progress is needed to overcome these challenges.

\section{Conclusions}

Several advances have been made in the last decade in the field of pediatric precision oncology heralding a new chapter in the fight against pediatric cancer. Although few pediatric institutions have started the initial journey towards precision oncology [48], several precision trials are now widely available for children with cancer. Publishing and sharing of clinical and genomic data will improve our understanding of targeted therapies leading to better patient management and further discoveries. The practical application of precision oncology in pediatric cancers is expected to grow exponentially with time and more investment in cancer research.

Author Contributions: All authors have contributed equally and substantially to the work.

Funding: This research received no external funding

Conflicts of Interest: The authors declare no conflict of interest. 


\section{References}

1. Kalia, M. Personalized oncology: Recent advances and future challenges. Metabolism 2013, 62 (Suppl. 1), S11-S14. [CrossRef] [PubMed]

2. Garraway, L.A.; Verweij, J.; Ballman, K.V. Precision oncology: An overview. J. Clin. Oncol. 2013, 31, $1803-1805$. [CrossRef] [PubMed]

3. Mendelsohn, J. Personalizing oncology: Perspectives and prospects. J. Clin. Oncol. 2013, 31, $1904-1911$. [CrossRef] [PubMed]

4. Seibel, N.L.; Janeway, K.; Allen, C.E.; Chi, S.N.; Cho, Y.J.; Glade Bender, J.L.; Kim, A.; Laetsch, T.W.; Irwin, M.S.; Takebe, N.; et al. Pediatric oncology enters an era of precision medicine. Curr. Probl. Cancer 2017, 41, 194-200. [CrossRef] [PubMed]

5. Ahmed, A.; Abedalthagafi, M. Cancer diagnostics: The journey from histomorphology to molecular profiling. Oncotarget 2016, 7, 58696-58708. [CrossRef]

6. Blumenthal, G.M.; Mansfield, E.; Pazdur, R. Next-generation sequencing in oncology in the era of precision medicine. JAMA Oncol. 2016, 2, 13-14. [CrossRef]

7. Horak, P.; Fröhling, S.; Glimm, H. Integrating next-generation sequencing into clinical oncology: Strategies, promises and pitfalls. ESMO Open 2016, 1, e000094. [CrossRef]

8. Van Dijk, E.L.; Auger, H.; Jaszczyszyn, Y.; Thermes, C. Ten years of next-generation sequencing technology. Trends Genet. 2014, 30, 418-426. [CrossRef]

9. Schwaederle, M.; Daniels, G.A.; Piccioni, D.E.; Fanta, P.T.; Schwab, R.B.; Shimabukuro, K.A.; Parker, B.A.; Kurzrock, R. On the road to precision cancer medicine: Analysis of genomic biomarker actionability in 439 Patients. Mol. Cancer Ther. 2015, 14, 1488-1494. [CrossRef]

10. Tsui, P.C.; Lee, Y.F.; Liu, Z.W.Y.; Piao, W.; Chiang, A.K.S.; Lui, V.W.Y. An update on genomic-guided therapies for pediatric solid tumors. Future Oncol. 2017, 13, 1345-1358. [CrossRef]

11. Gröbner, S.N.; Worst, B.C.; Weischenfeldt, J.; Buchhalter, I.; Kleinheinz, K.; Rudneva, V.A.; Johann, P.D.; Balasubramanian, G.P.; Segura-Wang, M.; Brabetz, S.; et al. The landscape of genomic alterations across childhood cancers. Nature 2018, 555, 321-327. [CrossRef] [PubMed]

12. Ma, X.; Liu, Y.; Liu, Y.; Alexandrov, L.B.; Edmonson, M.N.; Gawad, C.; Zhou, X.; Li, Y.; Rusch, M.C.; Easton, J.; et al. Pan-cancer genome and transcriptome analyses of 1699 paediatric leukaemias and solid tumours. Nature 2018, 555, 371-376. [CrossRef] [PubMed]

13. Rahal, Z.; Abdulhai, F.; Kadara, H.; Saab, R. Genomics of adult and pediatric solid tumors. Am. J. Cancer Res. 2018, 8, 1356-1386. [PubMed]

14. Worst, B.C.; van Tilburg, C.M.; Balasubramanian, G.P.; Fiesel, P.; Witt, R.; Freitag, A.; Boudalil, M.; Previti, C.; Wolf, S.; Schmidt, S.; et al. Next-generation personalised medicine for high-risk paediatric cancer patients-The INFORM pilot study. Eur. J. Cancer 2016, 65, 91-101. [CrossRef] [PubMed]

15. PDQ Pediatric Treatment Editorial Board. Childhood Cancer Genomics (PDQ ${ }^{\circledR}$ ): Health Professional Version. In PDQ Cancer Information Summaries [Internet]; National Cancer Institute: Bethesda, MD, USA, 2018; pp. 66-90.

16. Capper, D.; Stichel, D.; Sahm, F.; Jones, D.T.W.; Schrimpf, D.; Sill, M.; Schmid, S.; Hovestadt, V.; Reuss, D.E.; Koelsche, C.; et al. Practical implementation of DNA methylation and copy-number-based CNS tumor diagnostics: The Heidelberg experience. Acta Neuropathol. 2018, 136, 181-210. [CrossRef] [PubMed]

17. Kou, T.; Kanai, M.; Matsumoto, S.; Okuno, Y.; Muto, M. The possibility of clinical sequencing in the management of cancer. Jpn. J. Clin. Oncol. 2016, 46, 399-406. [CrossRef]

18. Maese, L.; Schiffman, J.D. The evidence for expanded genetic testing for pediatric patients with cancer. Future Oncol. 2018, 14, 187-190. [CrossRef]

19. Beltran, H.; Eng, K.; Mosquera, J.M.; Sigaras, A.; Romanel, A.; Rennert, H.; Kossai, M.; Pauli, C.; Faltas, B.; Fontugne, J.; et al. Whole-exome sequencing of metastatic cancer and biomarkers of treatment response. JAMA Oncol. 2015, 1, 466-474. [CrossRef]

20. Hirshfield, K.M.; Tolkunov, D.; Zhong, H.; Ali, S.M.; Stein, M.N.; Murphy, S.; Vig, H.; Vazquez, A.; Glod, J.; Moss, R.A.; et al. Clinical actionability of comprehensive genomic profiling for management of rare or refractory cancers. Oncologist 2016, 21, 1315-1325. [CrossRef] 
21. Mody, R.J.; Wu, Y.M.; Lonigro, R.J.; Cao, X.; Roychowdhury, S.; Vats, P.; Frank, K.M.; Prensner, J.R.; Asangani, I.; Palanisamy, N.; et al. Integrative clinical sequencing in the management of refractory or relapsed cancer in youth. JAMA 2015, 314, 913-925. [CrossRef]

22. Østrup, O.; Nysom, K.; Scheie, D.; Schmidt, A.Y.; Mathiasen, R.; Hjalgrim, L.L.; Olsen, T.E.; Skjøth-Rasmussen, J.; Henriksen, B.M.; Nielsen, F.C.; et al. Importance of comprehensive molecular profiling for clinical outcome in children with recurrent cancer. Front. Pediatr. 2018, 6, 114. [CrossRef] [PubMed]

23. Weidenbusch, B.; Richter, G.H.S.; Kesper, M.S.; Guggemoos, M.; Gall, K.; Prexler, C.; Kazantsev, I.; Sipol, A.; Lindner, L.; Nathrath, M.; et al. Transcriptome based individualized therapy of refractory pediatric sarcomas: Feasibility, tolerability and efficacy. Oncotarget 2018, 9, 20747-20760. [CrossRef] [PubMed]

24. Greenawalt, D.M.; Liang, W.S.; Saif, S.; Johnson, J.; Todorov, P.; Dulak, A.; Enriquez, D.; Halperin, R.; Ahmed, A.; Saveliev, V.; et al. Comparative analysis of primary versus relapse/refractory DLBCL identifies shifts in mutation spectrum. Oncotarget 2017, 8, 99237-99244. [CrossRef] [PubMed]

25. Groisberg, R.; Roszik, J.; Conley, A.; Patel, S.R.; Subbiah, V. The role of next-generation sequencing in sarcomas: Evolution from light microscope to molecular microscope. Curr. Oncol. Rep. 2017, $19,78$. [CrossRef] [PubMed]

26. Klein, M.E.; Parvez, M.M.; Shin, J.G. Clinical implementation of pharmacogenomics for personalized precision medicine: Barriers and solutions. J. Pharm. Sci. 2017, 106, 2368-2379. [CrossRef] [PubMed]

27. Deverka, PA.; Dreyfus, J.C. Clinical integration of next generation sequencing: Coverage and reimbursement challenges. J. Law Med. Ethics 2014, 42 (Suppl. 1), 22-41. [CrossRef]

28. Bavle, A.A.; Lin, F.Y.; Parsons, D.W. Applications of genomic sequencing in pediatric CNS tumors. Oncology (Williston Park) 2016, 30, 411-423.

29. Kline, C.N.; Joseph, N.M.; Grenert, J.P.; van Ziffle, J.; Talevich, E.; Onodera, C.; Aboian, M.; Cha, S.; Raleigh, D.R.; Braunstein, S.; et al. Targeted next-generation sequencing of pediatric neuro-oncology patients improves diagnosis, identifies pathogenic germline mutations, and directs targeted therapy. NeuroOncol. 2017, 19, 699-709. [CrossRef]

30. Oberg, J.A.; Glade Bender, J.L.; Sulis, M.L.; Pendrick, D.; Sireci, A.N.; Hsiao, S.J.; Turk, A.T.; Dela Cruz, F.S.; Hibshoosh, H.; Remotti, H.; et al. Implementation of next generation sequencing into pediatric hematology-oncology practice: Moving beyond actionable alterations. Genome Med. 2016, 8, 133. [CrossRef]

31. Marks, L.J.; Oberg, J.A.; Pendrick, D.; Sireci, A.N.; Glasser, C.; Coval, C.; Zylber, R.J.; Chung, W.K.; Pang, J.; Turk, A.T.; et al. Precision medicine in children and young adults with hematologic malignancies and blood disorders: The Columbia University experience. Front. Pediatr. 2017, 5, 265. [CrossRef]

32. Laetsch, T.W.; Roy, A.; Xu, L.; Black, J.O.; Coffin, C.M.; Chi, Y.Y.; Tian, J.; Spunt, S.L.; Hawkins, D.S.; Bridge, J.A.; et al. Undifferentiated sarcomas in children harbor clinically relevant oncogenic fusions and gene copy-number alterations: A report from the Children's Oncology Group. Clin. Cancer Res. 2018, 24, 3888-3897. [CrossRef] [PubMed]

33. Zhang, J.; Walsh, M.F.; Wu, G.; Edmonson, M.N.; Gruber, T.A.; Easton, J.; Hedges, D.; Ma, X.; Zhou, X.; Yergeau, D.A.; et al. Germline Mutations in Predisposition Genes in Pediatric Cancer. N. Engl. J. Med. 2015, 373, 2336-2346. [CrossRef] [PubMed]

34. Kuhlen, M.; Taeubner, J.; Brozou, T.; Wieczorek, D.; Siebert, R.; Borkhardt, A. Family-based germline sequencing in children with cancer. Oncogene 2018. [CrossRef] [PubMed]

35. Kuhlen, M.; Borkhardt, A. Trio sequencing in pediatric cancer and clinical implications. EMBO Mol. Med. 2018, 10, E8641. [CrossRef] [PubMed]

36. Brozou, T.; Taeubner, J.; Velleuer, E.; Dugas, M.; Wieczorek, D.; Borkhardt, A.; Kuhlen, M. Genetic predisposition in children with cancer-Affected families' acceptance of Trio-WES. Eur. J. Pediatr. 2018, 177, 53-60. [CrossRef] [PubMed]

37. Coury, S.A.; Schneider, K.A.; Schienda, J.; Tan, W.H. Recognizing and managing children with a pediatric cancer predisposition syndrome: A Guide for the Pediatrician. Pediatr. Ann. 2018, 47, e204-e216. [CrossRef] [PubMed]

38. Gallipoli, P.; Giotopoulos, G.; Huntly, B.J. Epigenetic regulators as promising therapeutic targets in acute myeloid leukemia. Ther. Adv. Hematol. 2015, 6, 103-119. [CrossRef]

39. Ramos, K.N.; Ramos, I.N.; Zeng, Y.; Ramos, K.S. Genetics and epigenetics of pediatric leukemia in the era of precision medicine. F1000Res 2018, 7, F1000. [CrossRef] 
40. Bhattacharjee, S.; Nandi, S. Synthetic lethality in DNA repair network: A novel avenue in targeted cancer therapy and combination therapeutics. IUBMB Life 2017, 69, 929-937. [CrossRef]

41. Chen, E.S. Targeting epigenetics using synthetic lethality in precision medicine. Cell. Mol. Life Sci. 2018, 75, 3381-3392. [CrossRef]

42. Shapira, A.; Livney, Y.D.; Broxterman, H.J.; Assaraf, Y.G. Nanomedicine for targeted cancer therapy: Towards the overcoming of drug resistance. Drug Resist. Updates 2011, 14, 150-163. [CrossRef] [PubMed]

43. Bar-Zeev, M.; Livney, Y.D.; Assaraf, Y.G. Targeted nanomedicine for cancer therapeutics: Towards precision medicine overcoming drug resistance. Drug Resist. Updates 2017, 31, 15-30. [CrossRef] [PubMed]

44. Santhosh, P.B.; Ulrih, N.P. Multifunctional superparamagnetic iron oxide nanoparticles: Promising tools in cancer theranostics. Cancer Lett. 2013, 336, 8-17. [CrossRef] [PubMed]

45. Huang, Y.; Mao, K.; Zhang, B.; Zhao, Y. Superparamagnetic iron oxide nanoparticles conjugated with folic acid for dual target-specific drug delivery and MRI in cancer theranostics. Mater. Sci. Eng. C Mater. Biol. Appl. 2017, 70, 763-771. [CrossRef] [PubMed]

46. Srivastava, S.; Riddell, S.R. Engineering CAR-T cells: Design concepts. Trends Immunol. 2015, 36, 494-502. [CrossRef]

47. Xia, A.L.; Wang, X.C.; Lu, Y.J.; Lu, X.J.; Sun, B. Chimeric-antigen receptor T (CAR-T) cell therapy for solid tumors: Challenges and opportunities. Oncotarget 2017, 8, 90521-90531. [CrossRef]

48. Mody, R.J.; Prensner, J.R.; Everett, J.; Parsons, D.W.; Chinnaiyan, A.M. Precision medicine in pediatric oncology: Lessons learned and next steps. Pediatr. Blood Cancer 2017, 64, e26288. [CrossRef]

(C) 2018 by the authors. Licensee MDPI, Basel, Switzerland. This article is an open access article distributed under the terms and conditions of the Creative Commons Attribution (CC BY) license (http://creativecommons.org/licenses/by/4.0/). 